Abstracta Iranica Abstracta Iranica

Revue bibliographique pour le domaine irano-aryen

Volume 30 | 2010

Comptes rendus des publications de 2007

\title{
La voix du chamane : étude sur les baxshi tadjiks et ouzbeks. Paris, IFEAC - L'Harmattan, 2007, 146 p. + ill. + append. (Coll. Centre-Asie)
}

\section{Rédaction}

\section{(2) OpenEdition}

\section{Journals}

Édition électronique

URL : http://journals.openedition.org/abstractairanica/38216

DOI : 10.4000/abstractairanica.38216

ISSN : 1961-960X

Éditeur :

CNRS (UMR 7528 Mondes iraniens et indiens), Éditions de l'IFRI

\section{Édition imprimée}

Date de publication : 8 avril 2010

ISSN : 0240-8910

\section{Référence électronique}

Rédaction, « La voix du chamane : étude sur les baxshi tadjiks et ouzbeks. Paris, IFEAC - L'Harmattan, 2007, 146 p. + ill. + append. (Coll. Centre-Asie) », Abstracta Iranica [En ligne], Volume 30 | 2010, document 361, mis en ligne le 08 avril 2010, consulté le 05 octobre 2020. URL : http:// journals.openedition.org/abstractairanica/38216; DOI : https://doi.org/10.4000/abstractairanica. 38216

Ce document a été généré automatiquement le 5 octobre 2020.

Tous droits réservés 


\title{
La voix du chamane : étude sur les
} baxshi tadjiks et ouzbeks. Paris, IFEAC - L'Harmattan, 2007, 146 p. + ill. + append. (Coll. Centre-Asie)

\author{
Rédaction
}

Cet ouvrage constitue une étude anthropologique du baxshi en Ouzbékistan et au nord $\mathrm{du}$ Tadjikistan. Basé sur un travail ethnographique local rendu de façon détaillé, il explore les différentes pratiques rituelles chamaniques de la région. La première partie du livre est consacrée à une étude systématique des différentes figures d'officiants de ces rituels (guérisseurs, devins, baxshis), de leurs statuts et pouvoirs respectifs. Les AA. présentent une histoire de l'évolution de leurs statuts et leurs pratiques pendant la période soviétique puis post-soviétique, en parallèle avec des portraits d'officiants qui rendent aisément compréhensible l'analyse de leurs pouvoirs. Le tout est accompagné de descriptions ethnographiques de rituels, ainsi que de transcriptions et traductions complètes des textes dits et chantés. Dans la seconde partie, les procédés chamaniques sont analysés sous les angles thérapeutique et religieux, et Jean During aborde alors les questions de contrôle (revenant ainsi sur les problématiques psychologiques) et d'extase, à partir des différentes expériences de tous les participants aux rituels. Le point de vue de l'Islam sur ces pratiques est également abordé à travers un entretien avec un mollah de la région de Boysun. La conclusion propose des détails sur l'élément soufi présent dans ces cérémonies, ainsi que sur la fusion de composantes turciques et iraniennes au sein des différentes figures de chamanes. 
INDEX

Thèmes : 17.1.Musique

\section{AUTEURS}

\section{RÉDACTION}

Directeur de la revue et secrétariats (Paris et Téhéran) 